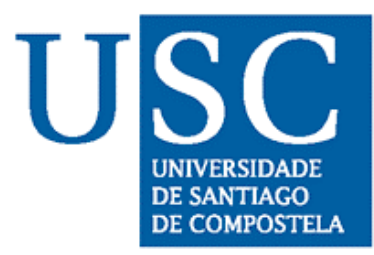

\title{
Sonogashira versus Stephens-Castro Mediated Synthesis of o-Phenylethynylbenzoic Acids, Convenient Precursors of 3-Phenylisocoumarins.
}

\author{
Francisco J. Reboredo, Juan C. Estévez* and Ramón J. Estévez* \\ Departamento de Química Orgánica. Universidade de Santiago de Compostela. \\ 15782 Santiago de Compostela, ESPAÑA \\ *Tel.: +34 981563100 ext. 14242. Fax: +34981591014 \\ e-mail: ramon.estevez@usc.es
}

\begin{abstract}
.
We describe herein two synthetic approaches to 3-phenyl-5-nitro-isocoumarines, both based on a nitro-facilitated cyclization of o-phenylethynylbenzoic acids obtained by Sonogashira or Stephens-Castro mediated coupling of $o$-yodobenzoic acids and phenylacetilenes.
\end{abstract}

\section{INTRODUCTION.}

$O$-diphenylacetilenes 3 have recently become powerfull synthetic tools on account of their easy preparation and their usefulness for the synthesis of heterocycles by heteroanulation reactions involving the $o$-substituent and the carbon-carbon triple bond. Thus, diphenylacetilenes 3 were first obtained in the sixties by Castro and co-workers ${ }^{1}$ by coupling processes that involved a nucleophilic attack of a phenyl-ethynyl cuprate on aryl halides, being applied to the synthesis of indoles (from $o$ aminodiphenylacetylenes), benzofurans (from $o$-hidroxydiphenylacetylenes), phtalides 4 and isocumarines 5 (from $o$-phenylethynylbenzoic acids), etc. But the drastic reaction conditions required limited the scope of this novel chemistry until seventies, when Songashira and co-workers ${ }^{2}$ developed a variant of the Castro's reaction which allowed the preparation of arylacetylenes $\mathbf{2}$ under milder conditions. 


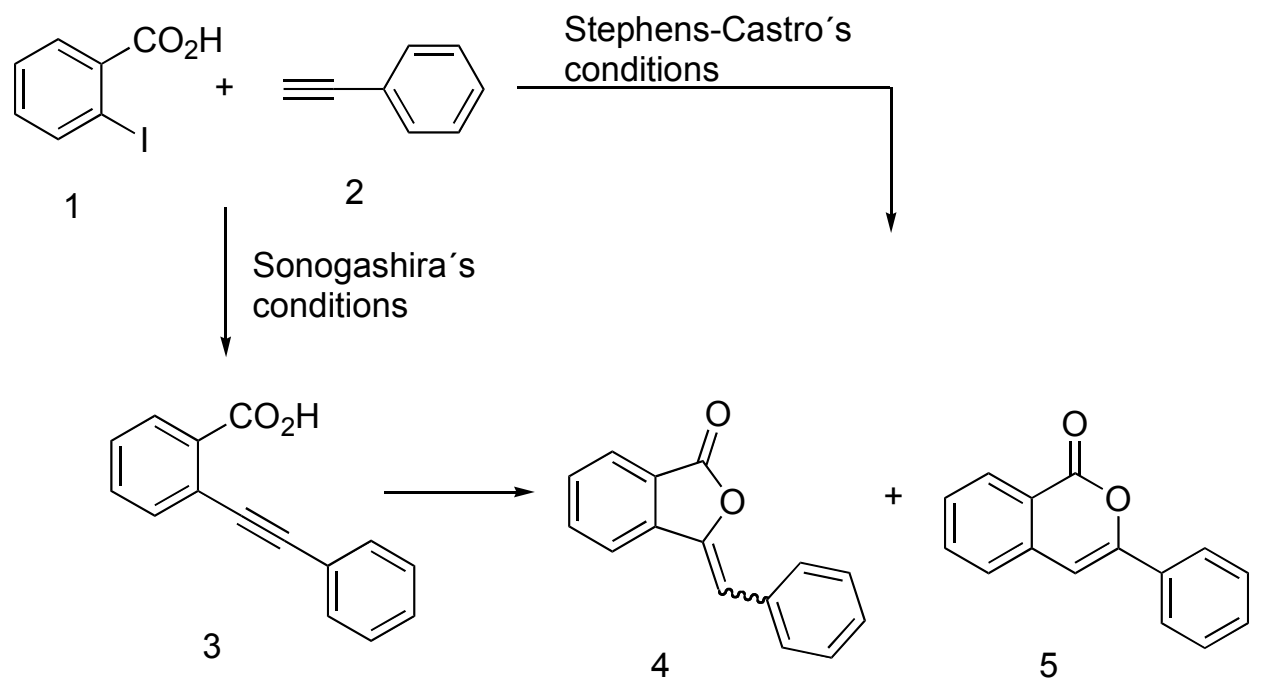

Scheme 1:

\section{RESULTS AND DISCUSSION.}

In connection with our previous work in this field, we present here our recent results concerning to the syntheses of the novel $o$-nitrophenylacetylenes $\mathbf{1 3}$ as synthetical precursors of the 3-phenylisocoumarins $\mathbf{1 0}$.

The synthesis of this key phenylacetylenes $\mathbf{1 3}$ was first approached by the StephensCastro methodology, starting from 2-phenylacetylenes 2 and 2-iodo-3-nitrobenzoic acid (8) prepared in a two steps sequence from 3-nitrophthalic acid $6 .^{3}$

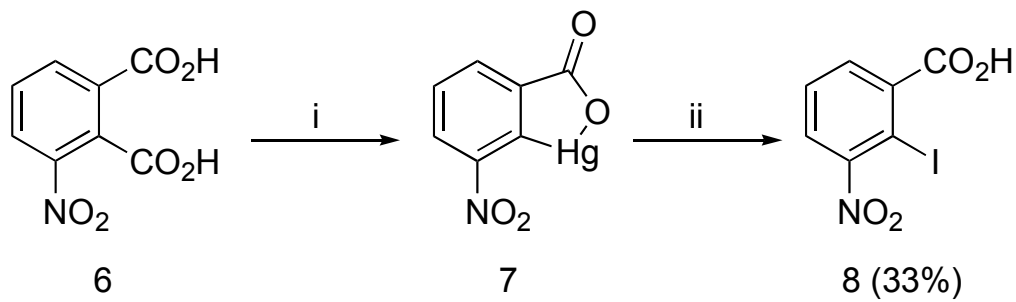

Scheme 2: i) $\mathrm{Hg}(\mathrm{OAc})_{2}, \mathrm{NaOH}(10 \%), \mathrm{AcOH}, \mathrm{H}_{2} \mathrm{O}$, ref., $72 \mathrm{~h}$. ii) $\mathrm{I}_{2}, \mathrm{KI}, \mathrm{NaOH}(1 \mathrm{M}), \mathrm{HCl}, \mathrm{AcOH}, \mathrm{H}_{2} \mathrm{O}$, ref., $12 \mathrm{~h}$

The phenylethynylcuprate (9a) was prepared treating the phenylacetilene (2a) with $\mathrm{CuI}$ in $\mathrm{NH}_{3}$, as described below. The coupling between 2-iodo-3-nitrobenzoic acid (8) and phenylethynylcuprate (9a) by the Stephens-Castro's conditions let us to the 5-nitro3-phenylisocoumarine 10a. The synthesis of the 3-(4-methoxyphenyl)-5-nitroisocumarine (10b) using the same conditions was no possible, instead the high temperature condition required for this coupling. 
<smiles>[R]c1ccc(C#C)cc1</smiles>

2 a) $\mathrm{R}=\mathrm{H}$

b) $\mathrm{R}=\mathrm{OMe}$

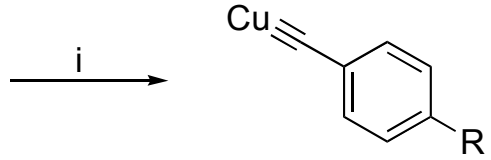

9 a) $\mathrm{R}=\mathrm{H}(51 \%)$

b) $\mathrm{R}=\mathrm{OMe}(56 \%)$<smiles>O=C(O)c1cccc([N+](=O)[O-])c1I</smiles>

8<smiles>[R]c1ccc(-c2cc3c([N+](=O)[O-])cccc3c(=O)o2)cc1</smiles>

10 a) $\mathrm{R}=\mathrm{H}(30 \%)$

b) $\mathrm{R}=\mathrm{OMe}(0 \%)$

Scheme 3: i) Cul, $\mathrm{NH}_{3}$ (ac.), EtOH, t.a., 10 min. ii) py, ref., 30 min

We studied a new approach to the synthesis of 5-nitro-3-phenylisocoumarins 10 involving a Sonogashira coupling. The esterification of 2-iodo-3-nitrobenzoic acid (8) with $\mathrm{MeOH}$ in acidic media, and the subsequent Pd catalyzed coupling ${ }^{4}$ of this ester $\mathbf{1 1}$ with phenylacetylene (2a) let us to methyl 3-nitro-2-phenylethynylbenzoate (12a). This ester was converted to the 5-nitro-3-phenylisocoumarin (10a) after a basic hidrolisis and treatment of the resulting acid $\mathbf{1 3}$ with refluxing pyridine.

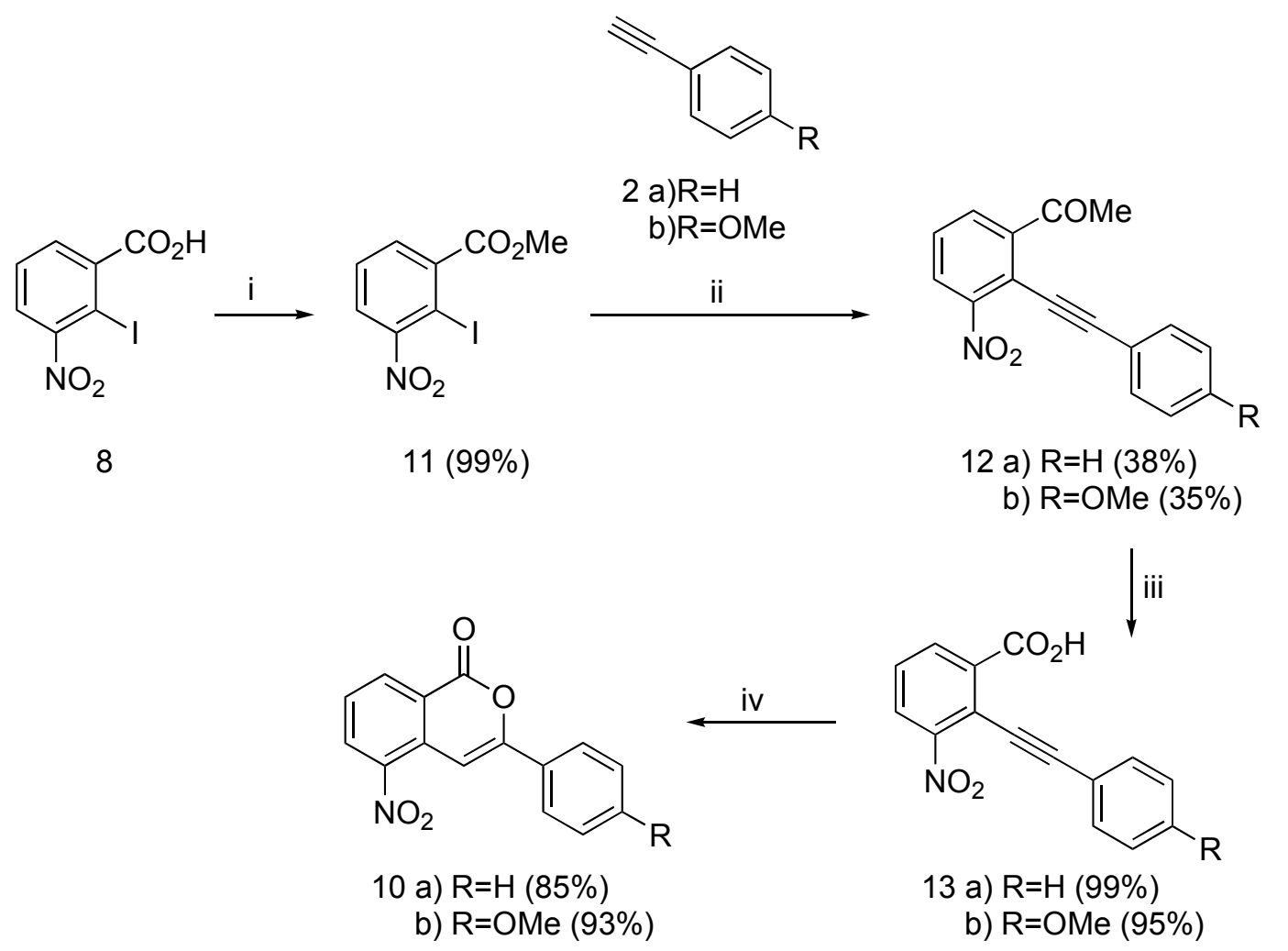

Scheme 4: i) $\mathrm{H}_{2} \mathrm{SO}_{4}$ (conc.), $\mathrm{MeOH}$, ref., 5 h. ii) $\left(\mathrm{PPh}_{3}\right)_{2} \mathrm{PdCl}_{2}$, Cul, THF, Et $\mathrm{t}_{3} \mathrm{~N}$, t.a., 4-20 h. iii) $\mathrm{NaOH}, \mathrm{MeOH}$, t.a., $5-20 \mathrm{~h}$. iv) $\mathrm{Cu}, \mathrm{py}, 110^{\circ} \mathrm{C}, 1-2 \mathrm{~h}$ 
The same conditions were employed to the synthesis of the 3-(4-methoxyphenyl)-5nitro-isocumarine (10b).

\section{CONCLUSION.}

The Stephens-Castro's conditions employed in this work for the synthesis of phenylisocumarines allowed us to synthesized in a two step sequence the 5-nitro-3phenylisocumarine (10a), but not the 3-(4-methoxyphenyl)-5-nitroisocumarine (10b) instead the high temperature requirements of this coupling. The modifications introduced by Sonogashira and co-workers permited us the synthesis of both desired isocumarines $\mathbf{1 0}$ in a four step sequence with a moderate overall yield.

\section{ACKNOWLEDGEMENTS.}

We thank the Spanish Ministry Science and Innovation and Xunta de Galicia for financial support.

1 Stephens, R.D.; Castro, C.E.; J.Org.Chem., 1963, 28, 3313.

2 Sonogashira, K.; Tohda, Y.;Hagihara, N.; Tetrahedron Lett., 1975, $50,4467$.

3 Luis, S.V.; Gaviña, F.; Ferrer, P.; Safont, V.S.; Torres, M.C.; Burguete, M.I. Tetrahedron, 1989, 45, 6281.

4 Bumagin, N. A.; Sukhom, L. I.; Luzikova, E. V.; Tolstaya, T. P.; Beletskaya, I. P. Tetrahedron Lett., 1996, 37, 897 